\title{
Snail leaps and bounds: drivers of the diel movement pattern of a large invertebrate, the Caribbean queen conch (Lobatus gigas), in a marginal inshore habitat
}

\author{
Dujon Antoine M. ${ }^{1,5}{ }^{*}$, Stieglitz Thomas C. ${ }^{1,2,3,6}$, Amice Erwan ${ }^{7}$, Webber Dale M. ${ }^{4}$
}

1 Inst Univ Europeen Mer, CNRS UMR 6539, Lab Sci Environm Marin, PI Nicolas Copernic, F-29280

Plouzane, France.

2 James Cook Univ, Ctr Trop Water \& Aquat Ecosyst Res, Townsville, Qld 4811, Australia.

3 James Cook Univ, Sch Engn \& Phys Sci, Townsville, Qld 4811, Australia.

4 VEMCO Ltd, Bedford, NS B4B 0L9, Canada.

5 Deakin Univ, Ctr Integrat Ecol, Sch Life \& Environm Sci, Waurn Ponds Campus, Waurn Ponds, Vic 3216, Australia.

${ }^{6}$ Aix Marseille Univ, CNRS, Ctr Rech \& Enseignement Geosci Environm CEREGE, IRD,Coll France, F13545 Aix En Provence, France.

7 Inst Univ Europeen Mer, CNRS UMR 6539, Lab Sci Environm Marin, PI Nicolas Copernic, F-29280

Plouzane, France.

*Corresponding author : Antoine M. Dujon, email address : antoine.dujon@yahoo.fr

\begin{abstract}
:
Understanding the relationship between the movements of animals and their environment is crucial for fisheries and species management. There is currently a lack of detailed information about the movement of slow-moving benthic species, especially for species of ecological or commercial importance. Here we document the relationship between diel movement and environmental parameters in a groundwater-fed coastal inlet for the queen conch (Lobatus gigas (Linnaeus, 1758)), an important fishery resource of the Caribbean region, using three-dimensional accelerometers and video cameras. Our results show immature queen conch $(n=9)$ spend most of their active time grazing, exhibiting two main distinct movements that we characterize as a leap and a drift that are mostly used to access new foraging resources. When overturned, they flip, producing a movement with the highest acceleration recorded to limit exposure and restore normal position. Movement patterns appear to be significantly affected by the oxygen concentration of the bottom water, with lower activity during low-oxygen levels in the morning (probability of 0.75 of observing 0 movement per hour) and maximum activity during the afternoon when oxygen concentration is at its maximum (probability of 0.80 of observing $>10$ movements per hour). Salinity and temperature had little effect on movement patterns. Our results confirm that highly variable marginal habitats like groundwater-fed inlets are suitable for juvenile conch growth and should be included in efficient conservation plans.
\end{abstract}


Keywords : movement recognition model, bio-logging, movement ecology, foraging behaviour, marine ecology, endangered species, fisheries, queen conch, Lobatus gigas 
Understanding the underlying behavioural reasons that explain why an animal moves is the main challenge in movement ecology. Within a habitat, animal movement is driven by the interaction of physiology, motion capacity, navigational capacity and environmental parameters (Turchin 1998, Nathan 2008). By impacting the ability of an animal to move, habitat quality is known to constrain species survival, reproduction, and population density as an animal has to move to feed, reproduce, and avoid predators or other unfavourable conditions (Turchin 1998, Nathan 2008). Large terrestrial and marine populations usually thrive in high quality habitats, while in comparison, marginal habitats (i.e. low-quality habitats) tend to be inhabited by smaller populations, and often require adaptation to specific local conditions to be able to persist over time (Bridle and Vines 2007, Kawecki 2008). However, marginal habitats can also offer protection against predators (Heithaus et al. 2007, Heithaus and Dill 2002, Bonnot et al. 2016), dramatic stochastic environmental disturbances (Crawford et al. 2018, Vrdoljak and Hart 2007) and can be used by animals to lower interindividual competition (Duarte et al. 2017, Larson 1980). While the movement pattern and behaviour of avian and terrestrial species in a range of habitats is well studied (Milner-Gulland et al. 2011, Viswanathan 2011), information about marine species remains comparatively more limited. The majority of the work on marine species focuses on mid to long-range movement of fast-moving birds, mammals, or fishes (Hussey et al. 2015). Comparatively the movement ecology of slow-moving benthic species such as gastropods, is poorly understood despite some of these species being of high ecological and commercial importance (Stoner et al. 1995, Leiva and Castilla 2001). Few

69 intertidal species (e.g. Lissmann 1945, Chelazzi et al. 1988, Little 1989, Rilov et al. 2005) and subtidal species (e.g. Coates et al. 2013, Jolivet et al. 2015) have been studied. Obtaining 
insights on the movement of slow moving benthic species is especially important in the context of fisheries management and climate change, mainly because it helps to identify important habitats involved in the different stages of a species life cycle (Grüss et al. 2011, Ogburn et al. 2017). Determining how movement data can be used to support conservation and management is a current key question in marine movement ecology (Hays et al. 2016). One such slow moving marine gastropod, the queen conch (Lobatus gigas, Bouchet et al. 2011) is one of the most important fishery resources in the Caribbean region. As a result, fished populations have been in decline for more than two decades (Theile 2001, Acosta 2006, Stoner et al. 2012a). This species is considered endangered and has been registered under Appendix II of the Convention on International Trade in Endangered Species of Wild Fauna and Flora (CITES) since 1992 (Acosta 2006). Queen conch biology and ecology have been extensively studied for decades (Randall 1964, Stoner 1989a, 1989b, Stoner et al. 1995, 2012b), including their home range (e.g. using acoustic telemetry, Glazer et al. 2003, Delgado and Glazer 2007, Stieglitz and Dujon 2017). However relatively little is known about their small-scale movement patterns, for which only short descriptions have been provided, and without significant resolution to understand movement patterns in relation with environmental drivers (Parker 1922).

In this study we established a library of small-scale queen conch movements using video footage and recorded the corresponding acceleration signal with a three-dimensional (3D) accelerometer. We then modelled the links between queen conch diel movement patterns with potential environmental drivers (e.g. salinity, dissolved oxygen concentration, temperature and time of day). We expected groundwater input to have an effect on dissolved oxygen concentration which should also have an effect on queen conch diel movement patterns. More specifically, based on the Stieglitz and Dujon (2017) preliminary study, we hypothesised that queen conch exhibit lower activity when dissolved oxygen concentration is 
96 low compared to periods of high oxygen concentration. Obtaining insights on queen conch

97 movement is especially important as this type of groundwater-fed marginal habitat (i.e. estuarine coastal inlets) could provide an efficient refuge for near-shore populations and may be able to contribute to an effective conservation management of this endangered and

100 socioeconomically highly valuable species (Stoner 2003, Grüss et al. 2011, Stieglitz and 101 Dujon 2017).

\section{Materials and methods}

104 Study site

105 Fieldwork was conducted in the coastal inlet of Xel-Ha $\left(20.317^{\circ} \mathrm{N},-87.358^{\circ} \mathrm{E}\right)$ on the west

106 coast of the Yucatan Peninsula (Mexico, Figure 1). The inlet was formed by karst dissolution

107 (Back et al. 1979, Stoessell et al. 1989) and is approximately $400 \mathrm{~m}$ long and $350 \mathrm{~m}$ wide

108 with a maximum depth of three meters (Stieglitz and Dujon 2017). The inlet is connected to 109 the Caribbean Sea by a 100-m wide channel. Xel-Ha receives considerable inputs of low-

110 salinity groundwater creating a permanent thermohaline stratification that can be easily

111 observed in the water column. In addition, the inlet is characterised by large diel variations in

112 concentrations of dissolved oxygen(Stoessell et al. 1989, Stieglitz and Dujon 2017). Bottom

113 substrates are mostly sandy, with small to large isolated rocks, bare sand, visible microalgal

114 mats or turtlegrass beds (Thallasia testudium, Stieglitz and Dujon 2017). A large population

115 of mostly juvenile queen conch inhabits the inlet (Valle-Esquivel 1998, Peel and Aldana

116 Aranda 2012). Xel-Ha is a private tourist park, and this population is protected from fishing.

\section{Tagging and observation of movement}

118 Queen conch were tagged using a VEMCO prototype tri-dimensional accelerometer

119 (12 cm long, $35 \mathrm{~g}$ mass in air with battery) with a $10 \mathrm{~Hz}$ acquisition frequency. To minimise 
animal disturbance, a diver carefully fixed the accelerometer onto the top of the apex of the

121 tagged individual in an arbitrary position using a plastic collar (typically behind the larger,

122 upfront row of spines), and without moving or removing the animal from its environment

123 (Figure 2). In addition, a small $5 \mathrm{~cm}$ long and $2 \mathrm{~cm}$ wide orange fishing float fixed at the

124 extremity of a ca $20 \mathrm{~cm}$ string was attached to the collar to visually help locating the animal

125 in the inlet. The total weight of the apparatus was $<70 \mathrm{~g}$ in air thus of a negligible weight in

126 water when attached to a shell range of 0.5 to $1.5 \mathrm{~kg}$ (Stieglitz and Dujon 2017). All queen

127 conch resumed movement and foraging within 15 minutes after deploying the tag. In April

128 2011, four individuals ( $\mathrm{C} 1$ to $\mathrm{C} 4$ ) were equipped with the accelerometer and continuous 3D

129 acceleration was recorded for approximately 48 hours for each animal, effectively recording a

130 cumulative time series over a duration of ca. 8 days (Table 1). In April 2012, five additional

131 queen conch were monitored for four to nine hours each (S1 to S3, J1 and J2, Table 1), and

132 their movements were concurrently recorded with two GoPro video cameras placed at

133 approximately $50 \mathrm{~cm}$ distance from the animal. Cameras were carefully moved and replaced

134 when the tagged conch was outside of the field of view or when camera memory was full. An

135 ethogram was then constructed based on visual examination of these video records. The video

136 records show no evidence of the tagged individuals attempting to remove their apparatus.

137 Similarly, based on the video footage and the movement of the float there was no evidence

138 that the individuals experienced strong currents (the float was almost always directly

139 vertically above the animal). The five April 2012 queen conch were a mix of immature

140 subadults (S1 to S3) and juveniles (J1 and J2, Table 1, Stoner et al. 2012, Boman et al. 2018).

141 We have no size measurement of the queen conch observed in April 2011 but we

142 nevertheless assume their day-to-day behaviour is similar to those observed in April 2012, as

143 they were representative of Xel-Ha population in this period (Table 1, Peel and Aldana

144 Aranda 2012, Stieglitz and Dujon 2017). 
146 Acceleration time series were first carefully calibrated to take into account the position of the

147 device on the queen conch shells (see Supplementary Methods 1). Then the static component

148 of the acceleration time series (equal to $1 \mathrm{~g}$ ) was removed by applying an order four low pass

149 Butterworth filter with a $4 \mathrm{~Hz}$ cut-off frequency on each acceleration axis (following Shepard

150 et al. 2008a). After filtering, the Overall Dynamic Body Acceleration (ODBA, expressed in

$151 \mathrm{~g}$ ), corresponding to the combined dynamic acceleration induced around the centre of an

152 animal's mass during a movement was calculated as (equation 1):

$$
\text { (1) } O D B A(g)=\sqrt{a_{x}^{2}+a_{y}^{2}+a_{z}^{2}}
$$

154 With $a_{x}$ the calibrated and filtered acceleration on the surge (the front-back axis), $a_{y}$ on the sway axis (the left-right axis) and $a_{z}$ on the heave axis (the vertical axis). The typical accelerometer noise, most likely due to waves and manual calibration, was inferior to $0.01 \mathrm{~g}$. Therefore, the queen conch were considered moving when the ODBA was $>0.01 \mathrm{~g}$ during $>0.2$ seconds and confirmed using video records (Figure 3).

All of the movements identified on the video records were classified as either 'leap',

160 'flip' or 'drift', and matched with their corresponding acceleration signal. We expected the

161 'flip' to be a relatively rare event. Therefore, to ensure we adequately captured this

162 movement type we manually overturned $\mathrm{J} 2$ and recorded the way that individual restored its

163 natural position ten times (Table 1). Manual overturning was performed at the very end of the video recording session before carrying $\mathrm{J} 2$ to the laboratory for calibrating the accelerometer axes. A suite of simple descriptors was subsequently calculated for each movement (Table 2). These descriptors were then used to build a flexible discriminant linear model to

167 automatically classify the different movement types ( $\mathrm{R}$ 'mde' package Hastie et al. 1994,

168 Hastie and Tibshirani 2013). Finally, this model was applied to the 48-hour time series data recorded in April 2011 to classify the movements of the four individuals for which there were 
170 no video recordings available. All calculations were performed in R software (Version 3.2.3,

171 R Development Core Team 2013).

172 Relationship between queen conch movement and environmental parameters.

173 To investigate if queen conch diel movement is influenced by ambient environmental

174 parameters, dissolved oxygen concentration, salinity and temperature at the sea floor of the

175 inlet were recorded at hourly intervals, using a pre-calibrated YSI multiprobe. The probe was

176 deployed within a few metres distance of the animal subjects. This data was obtained during

177 the April 2011 session for the animals $\mathrm{C} 1$ to $\mathrm{C} 3$, but not for $\mathrm{C} 4$ due to probe maintenance.

178 Movement data was first aggregated by calculating the number of movements

179 detected over a one-hour period. Then, logistic regression models were used to explore any

180 possible relationship between environmental parameters and queen conch movement (Zuur et

181 al. 2009). More specifically we linked the probability to observe $0, \geq 1, \geq 10$ and $\geq 25$

182 movement per hour (termed as $\mathrm{N}_{\text {mov }}$ and representing $21 \%, 79 \%, 42 \%$ and $20 \%$ of the

183 cumulative videos duration respectively) to hourly measurements of salinity, temperature,

184 dissolved oxygen concentration and the time of day. Odds ratios were used to compare the

185 relative odds of the occurrence of the outcome of interest (here the different levels of $\mathrm{N}_{\text {mov }}$ ).

186 If the odds ratio equals one, the exposure to an environmental parameter does not affect

187 movement, if $<1$ exposure is associated with a lower probability of occurrence of the

188 outcome, and if $>1$ exposure is associated with a higher probability of occurrence of the

189 outcome (see, Szumilas 2010). Throughout the manuscript all means are reported as (mean \pm

$190 s d$ ) except for the logistic regression results which are reported as (mean $\pm s e$ ). 


\section{Description of movement types}

193 Three different types of movements were identified from the recorded video data and termed as 'leap', 'drift' and 'flip' (Figure 3,4). Four different phases of the leaping movement can be identified (see Figure 3a, 4a, Electronic supplement 1): From a resting position (L1) the queen conch lifts the shell lip, (L2) using foot contraction the animal propels the shell

197 forward, (L3) the lip falls back on the sediment with gravity (L4). This movement is expressed chiefly in changes of sway and surge. Typical maximum ODBA acceleration is around $0.3 \mathrm{~g}$ and mean ODBA over a full movement cycle is $0.05 \pm 0.03 \mathrm{~g}$. Mean duration of a leap movement is $2.4 \pm 0.8$ seconds.

The drift movement corresponds to small movements a queen conch makes to rotate the shell to access new areas close by (Figure 3b, 4b, Electronic supplement 2). This movement is performed in one step (D2) and can be either a left or right turn. It has low acceleration values, with maximum ODBA values often $<0.1 \mathrm{~g}$ (mean ODBA $=0.02 \pm 0.01$ $g$ ). Mean duration of a drifting movement is $2.1 \pm 0.7$ seconds.

Queen conch encountering a slope or an obstacle (e.g. a rock or another queen conch) can sometimes lose their balance and their shell can turn upside down or fall on its side. The aperture of the shell is then oriented sideward or toward the sea surface. To restore their natural position, the queen conch flip their shell by first extruding their foot out of the shell (F1) to take support on the sea floor. Then an abrupt contraction of the foot muscle results in

211 a rotation of the shell (F2, F3; Figure 3c, 4c, Electronic supplement 3). If the aperture is not

212 facing the sea floor after a first flip, the animal will repeat this movement until the shell is in

213 the correct position. The flip is the movement with the highest acceleration values observed,

214 with a recorded maximum ODBA greater than $1 \mathrm{~g}$, a mean ODBA equal to $0.23 \pm 0.09 \mathrm{~g}$, and 215 a mean duration of $1.8 \pm 0.7$ seconds. Flips also produce the greatest recorded acceleration on 
216 the heave axis. While ten of those flips were artificially induced by manually overturning J2

217 and orienting the aperture toward the sea surface, a natural overturn was recorded on video,

218 when an untagged queen conch on a rocky slope collided with the monitored animal.

219 Under certain conditions, queen conch bury themselves in the sediment, and buried

220 queen conch are sometimes observed in the inlet. Burying behaviour was not observed during

221 our recordings. Similarly, mating behaviour was not observed. These two behaviours are

222 likely to produce distinct acceleration patterns different to those observed here but are either

223 rare or confined to periods outside of the observation period and thus not included in the

224 ethogram.

226 Building a statistical model for movement recognition

227 The flexible discriminant model was built from a total of 463 movements from the 2012

228 video and accelerometer records (403 leaps, 50 drifts and 10 flips, Table 1, Figure 5). Five

229 descriptors (MeanodBA, Mean $Z^{2}, T, M^{2} a_{Y^{2}}, M^{2} a_{X^{2}}$ ) allowed $95 \%$ of movements to be

230 correctly identified. Mean ${ }_{\mathrm{ODB}}$ alone allowed $89 \%$ of movements to be correctly identified

231 because of the considerable differences in acceleration ranges between the different

232 movement types. Other descriptors did not significantly improve the model performance $(<$

$2330.01 \%$ improvement). The 25 out of $463(6 \%)$ misclassified movements are leaps predicted

234 as drifts (16 movements) and drifts predicted as leaps (nine movements, Figure 5). 


\section{Application of movement recognition model}

236 The application of the model to the 48-hour time series data (without video recordings)

237 confirms queen conch predominantly perform leaps, which represents 90 to $95 \%$ of the

238 recorded movements (Figure 6). Drifts represent between 5 to $10 \%$ of total movements.

239 Video recordings confirmed that leaps and drifts are strongly related to grazing behaviour,

240 clearly identifiable by the movement of the proboscis at the surface of the sediment. Three

241 naturally produced flips were observed, all with a smaller maximum ODBA $(0.34,0.31$ and

$2420.44 \mathrm{~g}$ ) compared to the flips recorded by manually overturning the queen conch. This

243 suggests the natural overturns were not complete (e.g., if a queen conch slipped on the edge

244 of a rock or a slope). Incomplete turnover requires smaller movements to restore a standard

245 position.

246 Relationship between queen conch movement and environmental parameters.

247 Ambient dissolved oxygen concentration ranged from $3.2 \mathrm{mg} \mathrm{L}^{-1}$ to $9.7 \mathrm{mg} \mathrm{L}^{-1}$ (mean: $5.6 \pm$

$2481.3 \mathrm{mg} \mathrm{L}^{-1}$ ) following a daily cycle with a minimum concentration in the early morning hours

249 and a maximum concentration in the middle of the afternoon, typical for stratified estuarine

250 conditions (Figure 6a). Bottom salinity ranged between 19 and 33 (mean: $24.5 \pm 2.8$ ),

251 following a tidal cycle (Figure $6 \mathrm{~b}$ ). Bottom temperature variations were small and ranged

252 between $25.5^{\circ} \mathrm{C}$ and $28.6^{\circ} \mathrm{C}$ (mean: $26.8 \pm 0.5^{\circ} \mathrm{C}$ ) (Figure 6c).

Overall, salinity and temperature had little effect on the number of movements

recorded per hour (Table 3). The models including salinity and temperature were not significant while the model including the time of day were significant but with odd ratios close to one (indicating little effect on the number of movements per hour). Dissolved oxygen concentration was the environmental parameter explaining most of the queen conch activity pattern with the highest odds ratio (Table 3 ). The probability to observe $\geq 1, \geq 10$ and $\geq 25$ movements per hour increased with the dissolved oxygen concentration (odd ratios of 3.0, 1.8 
and 1.2 respectively, Table 3, Figure 7). During late morning and early afternoon activity increased until reaching a maximum around 4:00 pm when dissolved oxygen concentration is the highest (Figure 6a). In parallel, the probability of observing no movement during a onehour period decreased significantly (odd ratio of 0.3 ) with increased dissolved oxygen concentration. A reduction of activity (almost no movements) was observed around 6:00-7:00 am, corresponding to the ambient dissolved oxygen minimum and was associated with a probability to observe no movement during a one-hour period close to 0.75 (Figure 6a, Figure 7).

\section{Discussion}

\section{Model performance}

Most queen conch daily activity is spent on grazing. Movement is mainly composed of leaps interspaced with drifts. Flips are relatively rare occurrences. We showed that a simple model can be trained to classify those movement types with high performance. Only $6 \%$ of movements were misclassified by the predictive model. Upon closer inspection, leap and drift misclassifications were mainly due to a small rotation component (smaller than drifts) of the shell during some leap movements. Video records show those misclassified movements are clearly leaps occurring mostly on small local slopes, resulting in the distribution of the leap descriptor to overlap with the distribution of the drift movement descriptors. The low error rate of the model is acceptable and does not influence the ecological interpretation of queen conch movement (both leaps and drifts are mostly used to graze). Overall, queen conch movements are simple compared with those of animals like sharks, sea turtles, sea birds or marine mammals (e.g. Shepard et al. 2008b, Wilson et al. 2008, Dujon et al. 2018) or even

282 other marine benthic invertebrates (e.g. Robson et al. 2012, Jolivet et al. 2015). This simplicity allows models to be built that offer a very good representation of 'day-to-day' movement behaviours on the time scales of observation while more complex movement 
patterns would require advanced signal processing tools such as wavelet analysis and similar methods (e.g., Sakamoto et al. 2009, Whitney et al. 2010). Our simple method is easy to implement and to extend to new field sites and organisms (for example one of the other several species of fished gastropods or more broadly on large slow moving benthic marine species, Leiva and Castilla 2001).

\section{D accelerometry for studies of the movement ecology of marine snails}

291 The two main limiting factors of this work were (1) the memory capacity of the device,

292 which limited the recording time to $48 \mathrm{~h}$ with a $10 \mathrm{~Hz}$ acquisition frequency which does not allow long term monitoring of queen conch; and (2) the need to recapture the queen conch at the end of recording to download the data. Recently, higher performing accelerometers and bio-loggers have become available which overcome these limitations for future studies (Evans et al. 2013, Hussey et al. 2015).

By attaching the accelerometer to the shell, only movement resulting from foot muscle contraction was registered. When the shell is not moving, most of the body movement is restricted to moving the proboscis, especially during grazing. These body movements were not recorded but are a very important part of the animal's biology, as they allow the individual to feed. Energy production, oxygen consumption and movement are highly interrelated (Schmidt-Nielsen 1971, Garland Jr 1983) and acceleration has been shown to be a proxy of oxygen consumption and physiology of a large range of taxa (Halsey and Shepard 2009), such as bivalves (Robson et al. 2012), marine mammals (Jeanniard-du-Dot et al. 2017), amphibians (Halsey and White 2010) and marine birds (Murchie and Cooke 2011). In the case of marine benthic species, a careful calibration between acceleration and oxygen consumption could be used to provide an estimation of animal metabolism. energy expenditure is necessary to support their fast growth rates of body and shell and can 
310 represent, depending on species, $75 \%$ to $410 \%$ of the energy invested in somatic growth and

$3116 \%$ of the total respiratory losses (Palmer 1992). Currently, relatively little information is

312 available on queen conch physiology and oxygen consumption. The analyses of the co-

313 variations of activity and environmental parameters presented herein document that the

314 immature queen conch is able to deal with considerable variations in oxygen concentration

315 and salinity, and is still able to graze efficiently to sustain its growth, confirming preliminary

316 investigations (Stieglitz and Dujon 2017). This suggests physiological adaptations to the

317 quasi-estuarine habitat which is atypical for this species considered to be marine (Bridle and

318 Vines 2007, Kawecki 2008).

319 Queen conch is only one of several large marine snails in tropical and temperate waters and

320 relatively very little is known to date about the behaviour of such species, many of which are

321 important fisheries resources and play an important role in ecosystems (Stoner 1989b, Stoner

322 et al. 1995, Leiva and Castilla 2001). Successful conservation management of endangered

323 species critically depends on a good understanding of the species' movement and of their

324 interactions with the environment (Grüss et al. 2011, Ogburn et al. 2017) and we showed that

$3253 \mathrm{D}$ accelerometry is a powerful approach to obtain valuable insights for understanding the

326 fundamental ecology of marine snails.

\section{Ecological significance of queen conch movements}

328 The accelerogram and video footages revealed queen conch perform leaps for long distance movement, and drifts to rotate their shell. Both movement types are used to access new

330 foraging resources. Drifts are also used to find a better balance on slopes and rocks, or when

331 colliding with other queen conch. Contrary to most gastropods, members of the Strombus

332 genus do not crawl (Parker 1922, Lissmann 1945, Randall 1964, Little 1989). Occurrence of

333 flip movements is rare but very important (around one flip every 1000 movements); a queen 
conch must be able to return to its resting shell position when overturned, in order to avoid exposure to attack by a predator or, considering a longer period, to dying from starvation.

At least two known behavioural patterns (burial and mating) along with other potential behaviours associated with reproduction or ontogenetic habitat shift were not observed in this study. Here, the implications of those two movement with respect to shell acceleration are briefly discussed. Hesse (1979) describes the burying of queen conch as a succession of side to side foot movements and a pushing into the sand with the proboscis.

Based on these observations, acceleration records of burying behaviour should be comparable to several drift movements, and should follow each other closely. Robertson (1959) describes queen conch mating as the introduction of the male's contractile, black, spade-like verge through the syphonal notch of the female. If both snails' shells are immobile, it may be difficult to record and discriminate this behaviour in accelerometer studies.

\section{Temporal pattern of queen conch movement and response to environmental conditions}

In Xel-Ha inlet, the water column is permanently stratified due to the inflow of low-salinity groundwater (Back et al. 1979, Stoessell et al. 1989, Stieglitz and Dujon 2017). Typical for such estuarine conditions, oxygen exchange between the atmosphere and bottom water is inhibited by this stratification, and large diurnal bottom oxygen variations persist (Borsuk et al. 2001, Samal et al. 2006). During the day, the dissolved oxygen concentration increases due to photosynthetic processes, and night-time oxygen consumption by benthic and pelagic organisms lead to low-oxygen or hypoxic condition during the morning hours.

Most publications refer to the queen conch as a neritic animal mostly found on reefs and sea grass beds (see Stoner 2003 and references therein). We consider Xel-Ha as a marginal habitat for this marine species, because substantial variations in environmental conditions caused by the continuous groundwater inflow persist that are not usually observed in the species' typical marine habitat (Stoner 2003, Kawecki 2008, Stieglitz and Dujon 2017).Our 
results provide some elements of an answer to the question of how queen conch adapt to

360 those estuarine conditions. We showed that activity patterns of the queen conch follow the

361 diurnal variations of dissolved oxygen concentration. During low-oxygen periods queen

362 conch limit energetic expenses by suspending movement and grazing. Conversely queen

363 conchexhibited the greatest amount of activity during periods of ample oxygen supply. In

364 contrast, despite considerable diurnal variations in ambient salinity, the animals' activity

365 appears to be little affected by this variation on a day to day time scale. On the one hand this

366 is perhaps surprising given that the queen conch is considered a marine (i.e. not estuarine)

367 species and has an hemolymph composition close to sea water (Colin 1967), yet on the other

368 hand, some molluses have the ability to withstand variations in ambient salinity by storing

369 hyperosmotic hemolymph within the vascular system (Little 1981).

370 Despite being of lower quality, marginal habitats can play a role in the persistence of

371 species in situations where the core habitat is under substantial disturbance and where most of

372 the individuals inhabiting this key area are under threat of disappearing (e.g. roadside

373 grassland for native bees, Hopwood 2008; areas of low soil fertility and unsuitable for

374 farming for African mammals, Happold 1995 forest habitat for the European bison, Kerley et

375 al. 2012). In the case of the queen conch the main threats are the degradation of the core

376 habitats (e.g. nurseries and breeding grounds) by human activities and the removal of a large

377 proportion of mature individuals due to overfishing (Stoner and Ray-Culp 2000, Theile 2001,

378 Stoner 2003, Acosta 2006, Stoner et al. 2012b). Our result show the queen conch spend most

379 of its time foraging, which is key for sustaining the fast growth rates mesured in this

380 groundwater-fed marginal habitat (Valle-Esquivel 1998, Peel and Aldana Aranda 2012).This

381 also suggests the groundwater-fed coastal areas of the Yucatan peninsula could play a role in

382 the conservation of the queen conch while the issues of core habitats degradation and

383 overfishing are being resolved. 
concentration can have an important impact on queen conch behaviour, and despite the

periodic low oxygen concentrations experienced in this inlet, which affect movement for food intake, this habitat is a productive nursery ground with growth rates observed similar to those habitats in fully-marine conditions (Valle-Esquivel 1998, Peel and Aldana Aranda 2012).

\section{Acknowledgments}

391 We thank managers and staff at Xel-Ha (www.xelha.com) for access, excellent technical

392 support and sharing local knowledge, in particular R Saenz, E May, A Chevarria, S Perez and

393 G Maldonado from the section Dessarollo Sustentable. This study forms part of a larger

394 program on queen conch ecology carried out in collaboration between Parque Xel-Ha, the

395 Centro de Investigación y de Estudios Avanzados del Instituto Politécnico Nacional

396 CINVESTAV (Mexico) and the European Institute of Marine Studies IUEM France),

397 instigated by D Aldana-Aranda (CINVESTAV), L Chauvaud (IUEM) and R Saenz (Xel-Ha).

398 We thank L Chauvaud (IUEM) for technical and dive support, and for the many hours they

399 spent in the water tagging animals. J Peel advised on conch population dynamics in Xel-Ha.

400 We thank D Allen (VEMCO) for the loan of the prototype accelerometer, and for advice on

401 accelerometer data processing. We are grateful to Anna Miltiadous and two anonymous

402 reviewers for providing comments on the manuscript.

403

\section{Author contribution}

405 TCS conceived the study; AMD and EA conducted the fieldwork. AMD carried the 406 calibration study and analysed the data. DW provided technical assistance with the 407 accelerometer prototype data processing. AMD and TCS led the writing with input from DW. 
409

410

411

412

413

414

415

416

417

418

419

420

421

422

423

424

425

426

427

428

429

430

Acosta, C.A. 2006. Impending trade suspensions of Caribbean queen conch under CITES. Fisheries 31(12): 601-606.

Back, W., Hanshaw, B.B., Pyle, T.E., Plummer, L.N., and Weidie, A.E. 1979. Geochemical significance of groundwater discharge and carbonate solution to the formation of Caleta Xel Ha, Quintana Roo, Mexico. Water Resour. Res. 15(6): 1521-1535.

Boman, E.M., Graaf, M. d., Nagelkerke, L.A.J., Stoner, A.W., Bissada, C.E., Avila-Poveda, O.H., Baqueiro-Cardenas, E.R., and Smaal, A.C. 2018. Variability in size at maturity and reproductive season of queen conch Lobatus gigas (Gastropoda: Strombidae) in the Wider Caribbean Region. Fish. Res. 201: 18-25.

Bonnot, N., Morellet, N., Hewison, A.J.M., Martin, J.-L., Benhamou, S., and ChamailléJammes, S. 2016. Black-tailed deer (Odocoileus hemionus sitkensis) adjust habitat selection and activity rhythm to the absence of predators. Can. J. Zool. 94(6): 385-394.

Borsuk, M.E., Stow, C.A., Luettich Jr, R.A., Paerl, H.W., and Pinckney, J.L. 2001. Modelling oxygen dynamics in an intermittently stratified estuary: estimation of process rates using field data. Estuar. Coast. Shelf Sci. 52(1): 33-49.

Bouchet, P., Kantor, Y.I., Sysoev, A., and Puillandre, N. 2011. A new operational classification of the Conoidea (Gastropoda). J. Molluscan Stud. 77(3): 273-308.

Bridle, J.R., and Vines, T.H. 2007. Limits to evolution at range margins: when and why does adaptation fail? Trends Ecol. Evol. 22(3): 140-147.

Chelazzi, G., Focardi, S., and Deneubourg, J.-L. 1988. Analysis of movement patterns and orientation mechanisms in intertidal chitons and gastropods. In Behavioral adaptation to intertidal life. Plenum Press, London and New York. pp. 173-184. 
431 Coates, J.H., Hovel, K.A., Butler, J.L., Klimley, A.P., and Morgan, S.G. 2013. Movement and home range of pink abalone Haliotis corrugata: implications for restoration and population recovery. Mar. Ecol. Prog. Ser. 486: 189-201.

Colin, L. 1967. Ionic regulation in the queen conch, Strombus Gigas (Gastropoda, Prosobranchia). J. Exp. Biol. 46: 459-474.

Crawford, J.C., Nielsen, C.K., and Schauber, E.M. 2018. Survival and habitat use of sympatric lagomorphs in bottomland hardwood forests. Can. J. Zool. 96(7): 713-722.

Delgado, G.A., and Glazer, R.A. 2007. Interactions between translocated and native queen conch Strombus gigas: evaluating a restoration strategy. Endanger. Species Res. 3: 259-

Duarte, R.C., Flores, A.A.V., Vinagre, C.., and Leal, M.C. 2017. Habitat-dependent niche 442 partitioning between colour morphs of the algal-dwelling shrimp Hippolyte obliquimanus. Mar. Biol. 164(11): 215.

Dujon, A.M., Schofield, G., Lester, R.E., Papafitsoros, K., and Hays, G.C. 2018. Complex movement patterns by foraging loggerhead sea turtles outside the breeding season identified using Argos-linked Fastloc-Global Positioning System. Mar. Ecol. 39(1):

Evans, K., Lea, M.A., and Patterson, T.A. 2013. Recent advances in bio-logging science: technologies and methods for understanding animal behaviour and physiology and their environments. Deep. Res. Part II 88-89: 1-6.

Garland Jr, T. 1983. Scaling the ecological cost of transport to body mass in terrestrial mammals. Am. Nat. 121(4): 570-587. home ranges using acoustic telemetry: implications for the design of marine fishery 
reserves. Gulf Caribb. Res. 14(2): 79-89.

456

457

458

459

460

461

462

463

464

465

466

467

468

469

470

471

472

473

474

475

476

477

478

Grüss, A., Kaplan, D.M., Guénette, S., Roberts, C.M., and Botsford, L.W. 2011. Consequences of adult and juvenile movement for marine protected areas. Biol. Conserv. 144(2): 692702.

Halsey, L.G., and Shepard, E.L.C. 2009. The relationship between oxygen consumption and body acceleration in a range of species. Comp Biochem Physiol A Mol Integr Physiol 152(2): 197-202.

Halsey, L.G., and White, C.R. 2010. Measuring energetics and behaviour using accelerometry in cane toads Bufo marinus. PLoS One 5(4): e10170.

Happold, D.C.D. 1995. The interactions between humans and mammals in Africa in relation to conservation: a review. Biodivers. Conserv. 4(4): 395-414. doi:10.1007/BF00058424.

Hastie, T., and Tibshirani, R. 2013. Mixture and flexible discriminant analysis. R package, version 0.4-4. Standford University, cran.r-project.org.

Hastie, T., Tibshirani, R., and Buja, A. 1994. Flexible discriminant analysis by optimal scoring. J. Am. Stat. Assoc. 89(428): 1255-1270.

Hays, G.C., Ferreira, L.C., Sequeira, A.M.M., Meekan, M.G., Duarte, C.M., Bailey, H., Bailleul, F., Bowen, W.D., Caley, M.J., Costa, D.P., Eguíluz, V.M., Fossette, S., Friedlaender, A.S., Gales, N., Gleiss, A.C., Gunn, J., Harcourt, R., Hazen, E.L., Heithaus, M.R., Heupel, M., Holland, K., Horning, M., Jonsen, I., Kooyman, G.L., Lowe, C.G., Madsen, P.T., Marsh, H., Phillips, R.A., Righton, D., Ropert-Coudert, Y., Sato, K., Shaffer, S.A., Simpfendorfer, C.A., Sims, D.W., Skomal, G., Takahashi, A., Trathan, P.N., Wikelski, M., Womble, J.N., and Thums, M. 2016. Key questions in marine megafauna movement ecology. Trends Ecol. Evol. 31(6): 463-475. Elsevier Ltd.

Heithaus, M.R., and Dill, L.M. 2002. Food availability and tiger shark predation risk influence 
bottlenose dolphin habitat use. Ecology 83(2): 480-491.

480 Heithaus, M.R., Frid, A., Wirsing, A.J., Dill, L.M., Fourqurean, J.W., Burkholder, D., 481 Thomson, J., and Bejder, L. 2007. State-dependent risk-taking by green sea turtles mediates top-down effects of tiger shark intimidation in a marine ecosystem. J. Anim. Ecol. 76(5): 837-844.

Hesse, K.O. 1979. Movement and migration of the queen conch, Strombus gigas, in the Turk and Caicos Islands. Bull. Mar. Sci. 29(3): 303-311.

Hopwood, J.L. 2008. The contribution of roadside grassland restorations to native bee conservation. Biol. Conserv. 141(10): 2632-2640. doi:10.1016/j.biocon.2008.07.026.

Hussey, N.E., Kessel, S.T., Aarestrup, K., Cooke, S.J., Cowley, P.D., Fisk, A.T., Harcourt, R.G., Holland, K.N., Iverson, S.J., Kocik, J.F., Mills Flemming, J.E., and Whoriskey, F.G. 2015. Aquatic animal telemetry: a panoramic window into the underwater world. Science 348(6240): 1221-1231.

Jeanniard-du-Dot, T., Guinet, C., Arnould, J.P.Y., Speakman, J.R., and Trites, A.W. 2017. Accelerometers can measure total and activity-specific energy expenditures in free-

Jolivet, A., Chauvaud, L., Thébault, J., Robson, A.A., Dumas, P., Amos, G., and Lorrain, A. 2015. Circadian behaviour of Tectus (Trochus) niloticus in the southwest Pacific inferred from accelerometry. Mov. Ecol. 3(1): 26. 342. refugee species concept and the European bison: King of the forest or refugee in a 

0587.2011.07146.x.

Larson, R.J. 1980. Competition, habitat selection, and the bathymetric segregation of two rockfish (Sebastes) species. Source Ecol. Monogr. Ecol. Monogr. 50(502): 221-239.

Leiva, G.E., and Castilla, J.C. 2001. A review of the world marine gastropod fishery: evolution of catches, management and the Chilean experience. Rev. Fish Biol. Fish. 11(4): 283300.

Lissmann, H. 1945. The mechanism of locomotion in gastropod molluscs II. Kinetics. J. Exp. Biol. 22: 37-50.

Little, C. 1981. Osmoregulation and excretion in prosobranch gastropods Part I: physiology and biochemistry. J. Molluscan Stud. 47(3): 221-247.

Little, C. 1989. Factors governing patterns of foraging activity in littoral marine herbivorous molluscs. J. Molluscan Stud. 55(2): 273-284.

Milner-Gulland, E.J., Fryxell, J.M., and Sinclair, A.R.E. 2011. Animal migration: a synthesis. Edited byE.J. Milner-Gulland, J.M. Fryxell, and A.R.E. Sinclair. Oxford University Press, Oxford.

Murchie, K.J., and Cooke, S.J. 2011. Estimates of field activity and metabolic rates of bonefish (Albula vulpes) in coastal marine habitats using acoustic tri-axial accelerometer transmitters and intermittent-flow respirometry. J. Exp. Mar. Bio. Ecol. 396(2): 147-155.

Nathan, R. 2008. An emerging movement ecology paradigm. Proc. Natl. Acad. Sci. U. S. A. 105(49): 19050-19051.

Ogburn, M.B., Harrison, A.-L., Whoriskey, F.G., Cooke, S.J., Mills Flemming, J.E., and Torres, L.G. 2017. Addressing challenges in the application of animal movement ecology 

to aquatic conservation and management. Front. Mar. Sci. 4: 1-7.

527 Palmer, A. 1992. Calcification in marine molluscs: how costly is it? PNAS 89(4): 1379-1382.

528 Parker, G.H. 1922. The leaping of the stromb (Strombus gigas Linn.). J. Exp. Zool. 36(2): 204529 209.

530

Peel, J.R., and Aldana Aranda, D. 2012. Growth and population assessment of the queen conch Strombus gigas (Mesogastropoda: Strombidae) by capture mark-recapture sampling in a natural protected area of the Mexican Caribbean. Rev. Biol. Trop. 60: 127-137.

R Development Core Team. 2013. R: a language and environment for statistical computing. R Foundation for Statistical Computing, Vienna, Austria.

Randall, J.E. 1964. Contributions to the biology of the queen conch, Strombus gigas. Bull. Mar. Sci. 14(2): 246-295.

Rilov, G., Gasith, A., and Benayahu, Y. 2005. Effect of disturbance on foraging: whelk activity on wave-exposed rocky shores with minimal tidal range. Mar. Biol. 147(2): 421-428.

Robertson, R. 1959. Observations on the spawn and veligers of conchs (Strombus) in the Bahamas. J. Molluscan Stud. 33(4): 164-171.

Robson, A.A., Chauvaud, L., Wilson, R.P., and Halsey, L.G. 2012. Small actions, big costs: the behavioural energetics of a commercially important invertebrate. J. R. Soc. Interface

Sakamoto, K.Q., Sato, K., Ishizuka, M., Watanuki, Y., Takahashi, A., Daunt, F., and Wanless, S. 2009. Can ethograms be automatically generated using body acceleration data from free-ranging birds? PLoS One 4(4): e5379.

547 Samal, N.R., Roy, D., Mazumdar, A., and Bose, B. 2006. Influence of thermal stratification on 548 dissolved oxygen in Subhas Sarobar, Kolkata. J. Curr. Sci. 1: 259-266. 
549 Schmidt-Nielsen, K. 1971. Locomotion: energy cost of swimming, flying, and running. Science 177: 222-228.

551

552

Shepard, E.L.C., Wilson, R.P., Halsey, L.G., Quintana, F., Laich, A.G., Gleiss, A.C., Liebsch, N., Myers, A.E., and Norman, B. 2008a. Derivation of body motion via appropriate smoothing of acceleration data. Aquat. Biol. 4: 235-241.

Shepard, E.L.C., Wilson, R.P., Quintana, F., Laich, A.G., Liebsch, N., Albareda, D.A., Halsey, L.G., Gleiss, A.C., Morgan, D.T., and Myers, A.E. 2008b. Identification of animal movement patterns using tri-axial accelerometry. Endanger. Species Res. 10(47-60): 2.1.

Stieglitz, T.C., and Dujon, A.M. 2017. A groundwater-fed coastal inlet as habitat for the Caribbean queen conch Lobatus gigas - an acoustic telemetry and space use analysis. Mar. Ecol. Prog. Ser. 571: 139-152.

Stoessell, R.K., Ward, W.C., Ford, B.H., and Schuffert, J.D. 1989. Water chemistry and CaCO3 dissolution in the saline part of an open-flow mixing zone, coastal Yucatan Peninsula, Mexico. Geol. Soc. Am. Bull. 101(2): 159-169.

Stoner, A.W. 1989a. Density-dependent growth and grazing effects of juvenile queen conch Strombus gigas L. in a tropical seagrass meadow. J. Exp. Mar. Bio. Ecol. 130(2): 119133.

Stoner, A.W. 1989b. Winter mass migration of juvenile queen conch Strombus gigas and their influence on the benthic environment. Mar. Ecol. Prog. Ser. 56(1): 99-104.

Stoner, A.W. 2003. What constitutes essential nursery habitat for a marine species? A case study of habitat form and function for queen conch. Mar. Ecol. Prog. Ser. 257: 275-289.

Stoner, A.W., Davis, M.H., and Booker, C.J. 2012a. Abundance and population structure of queen conch inside and outside a marine protected area: repeat surveys show significant declines. Mar. Ecol. Prog. Ser. 460: 101-114. 
Stoner, A.W., Mueller, K.W., Brown-Peterson, N.J., Davis, M.H., and Booker, C.J. 2012b. Maturation and age in queen conch (Strombus gigas): Urgent need for changes in harvest criteria. Fish. Res. 131: 76-84.

Stoner, A.W., and Ray-Culp, M. 2000. Evidence for Allee effects in an over-harvested marine gastropod: Density-dependent mating and egg production. Mar. Ecol. Prog. Ser. 202: 297302. doi:10.3354/meps202297.

Stoner, A.W., Ray, M., and Waite, J.M. 1995. Effects of a large herbivorous gastropod on macrofauna communities in tropical seagrass meadows. Mar. Ecol. Prog. Ser. 121(1-3): $125-138$.

Szumilas, M. 2010. Explaining odds ratios. J. Can. Acad. Child Adolesc. Psychiatry 19(3): $227-229$.

Theile, S. 2001. Queen conch fisheries and their management in the Caribbean. Technical report to the CITES secretariat in completion of contract A-2000/01.

Turchin, P. 1998. Quantitative analysis of movement: measuring and modeling population redistribution in animals and plants. Sinauer Associates Incorporated, Sunderland, Massachusetts, USA.

Valle-Esquivel, M. 1998. Growth of queen conch, Strombus gigas, In Xel-ha, Quintana Roo, Mexico. Proc Gulf Caribb Fish Inst 50: 66-77.

Viswanathan, G.M., Da Luz, M.G.E., Raposo, E.P., and Stanley, H.E. 2011. The physics of foraging: an introduction to random searches and biological encounters. Cambridge University Press, New York, USA.

Vrdoljak, S.M., and Hart, R.C. 2007. Groundwater seeps as potentially important refugia for freshwater fishes on the Eastern Shores of Lake St Lucia, KwaZulu-Natal, South Africa. African J. Aquat. Sci. 32(2): 125-132. 
597 Whitney, N.M., Pratt Jr, H.L., Pratt, T.C., and Carrier, J.C. 2010. Identifying shark mating 598 behaviour using three-dimensional acceleration loggers. Endanger. Species Res. 10: 71$599 \quad 82$.

600 Wilson, R.P., Shepard, E.L.C., and Liebsch, N. 2008. Prying into the intimate details of animal 601 lives: use of a daily diary on animals. Endanger. Species Res. 4(1-2): 123-137.

602 Zuur, A.F., Ieno, E.N., Walker, N.J., Saveliev, A.A., and Smith, G.M. 2009. Mixed effects 603 models and extensions in ecology with R. Springer Berlin Heidelberg, Berlin, Germany. 604 605 
607 Figure 1: Location of the ground-water-fed Xel-Ha inlet (represented by a black square) on the Yucatan Peninsula (Mexico).

609

610 Figure 2: Photography of a queen conch (Lobatus gigas) carrying a 3D accelerometer (back

611 cylinder in A) recording the shell movements (in B) in Xel-Ha inlet in 2012. The proboscis

612 (showed by the red arrow in C) extrudes from the shell during grazing and its movement is

613 not recorded by the accelerometer.

614

615 Figure 3: The three main movements of the queen conch (Lobatus gigas) and its typical 616 accelerograms: (a) leap - the most frequent movements mainly used for grazing and long617 distance travels, (b) drift - used to rotate the shell to access close areas of sediment and (c) flip 618 - made when the conch shell is overturned. Note the scale differences on the y-axis for the three 619 movement types.

620

621 Figure 4: Visual representation of the three-main type of queen conch (Lobatus gigas) movement: (a) the leap, (b) the drift, (c) the flip. The section, L1 to L4, D1 to D2 and F1 to F4 correspond to the same naming on Figure 3.

Figure 5: Visual representation of the flexible discriminant model built using the acceleration time series and video record of the five 2012 individuals. Five descriptors were retained to build the model: Mean ${ }_{\mathrm{ODBA}}, \mathrm{Mean}_{\mathrm{Z}^{2}}, \mathrm{~T}, \mathrm{Mean}_{\mathrm{Y}^{2}}$ and Mean $\mathrm{X}^{2}$. The leaps (white circles, $n=$ 403), drifts (black circles, $n=50$ ) and flips (white squares, $n=10$ ) are relatively well discriminated with an error rate of less than $6 \%$ (leaps predicted as drift, $n=16$ as grey 630 circles and drifts predicted as leaps, $n=9$ as grey squares). 
632 Figure 6: (a-c) Overall Dynamic Body Acceleration (ODBA, in $g$ ) records of four queen conch 633 (Lobatus gigas) recorded over a period of eight consecutive days in April 2011. Each vertical 634 bar indicates a conch movement and its associated ODBA (leap as grey bar, drift has black 635 bar). White circles represent flip movements. Movements were classified using the flexible 636 discriminant model. Dashed vertical lines indicate the start and end of each individual conch 637 record. No data was recorded during the period marked with a ø. In (a) oxygen, (b) salinity and 638 (c) temperature variations are represented as solid black lines. Oxygen concentration follows a 639 diel pattern $\left(\mathrm{mg} \mathrm{L}^{-1}\right)$, while the salinity and temperature $\left({ }^{\circ} \mathrm{C}\right)$ follow a tidal pattern.

640

641 Figure 7: Probability curves of the logistic regression models linking the probability of 642 observing: (a) no movement $\left(N_{\text {mov }}=0\right.$, middle black line), (b) at least one movement ( $N_{\text {mov }} \geq$ 6431 , middle black line) (c) at least ten movements $\left(N_{m o v} \geq 10\right.$, middle black line) and (d) at least 64425 movement $\left(N_{\text {mov }} \geq 25\right.$, middle black line) per hour in function of the dissolved oxygen 645 concentration. Grey dashed lines represent the 95\% confidence interval for each model. 
$646 \quad$ Figure 1

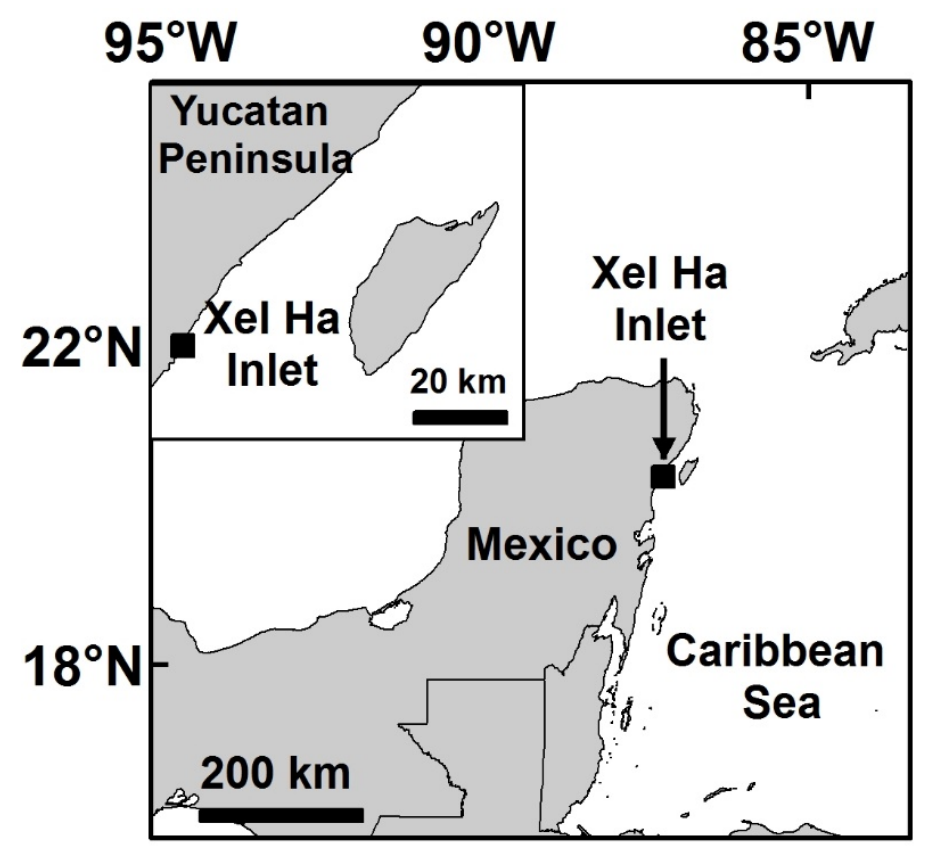


648 Figure 2:

649

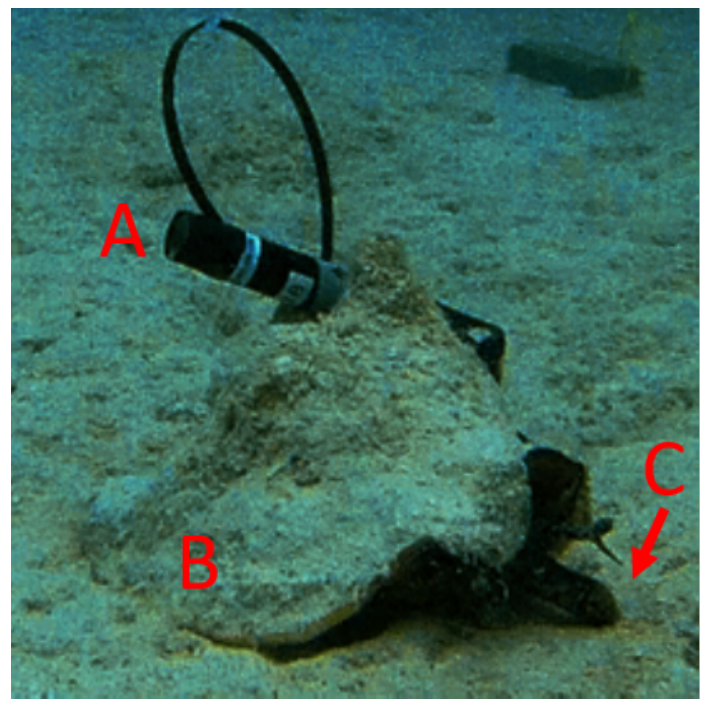

650 
651 Figure 3:
(a) Leap
(b) Drift
(c) Flip
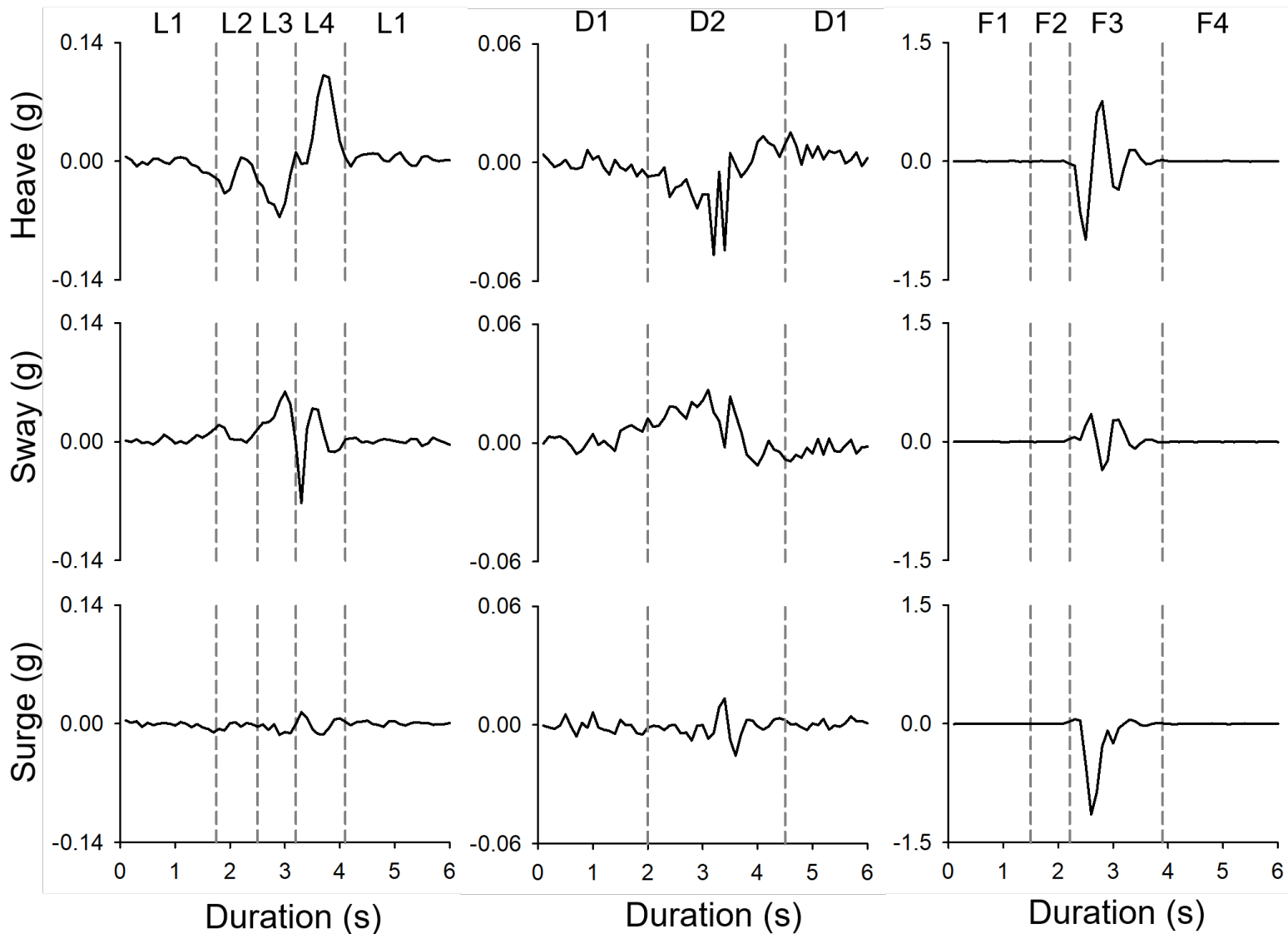

652

653 
654 Figure 4:

(a) Leap
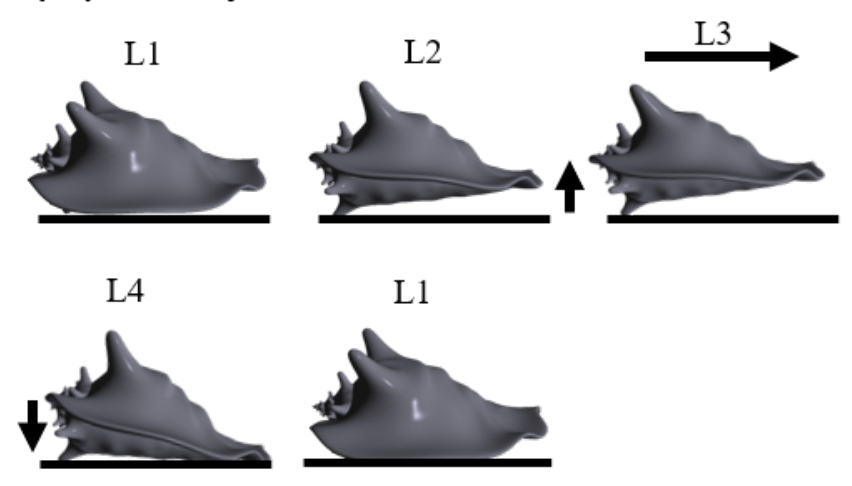

(b) Drift

D1

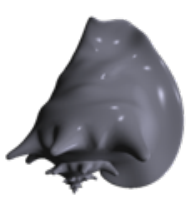

(c) Flip
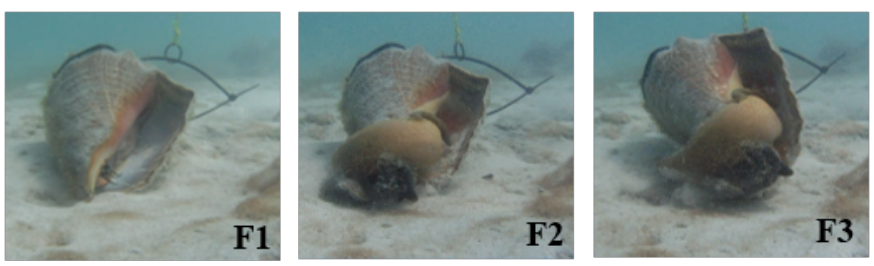

D2

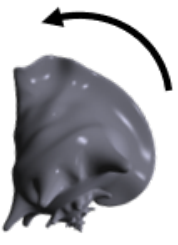

F3

655

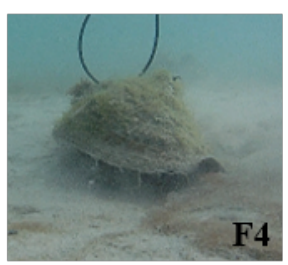

656 
657 Figure 5:

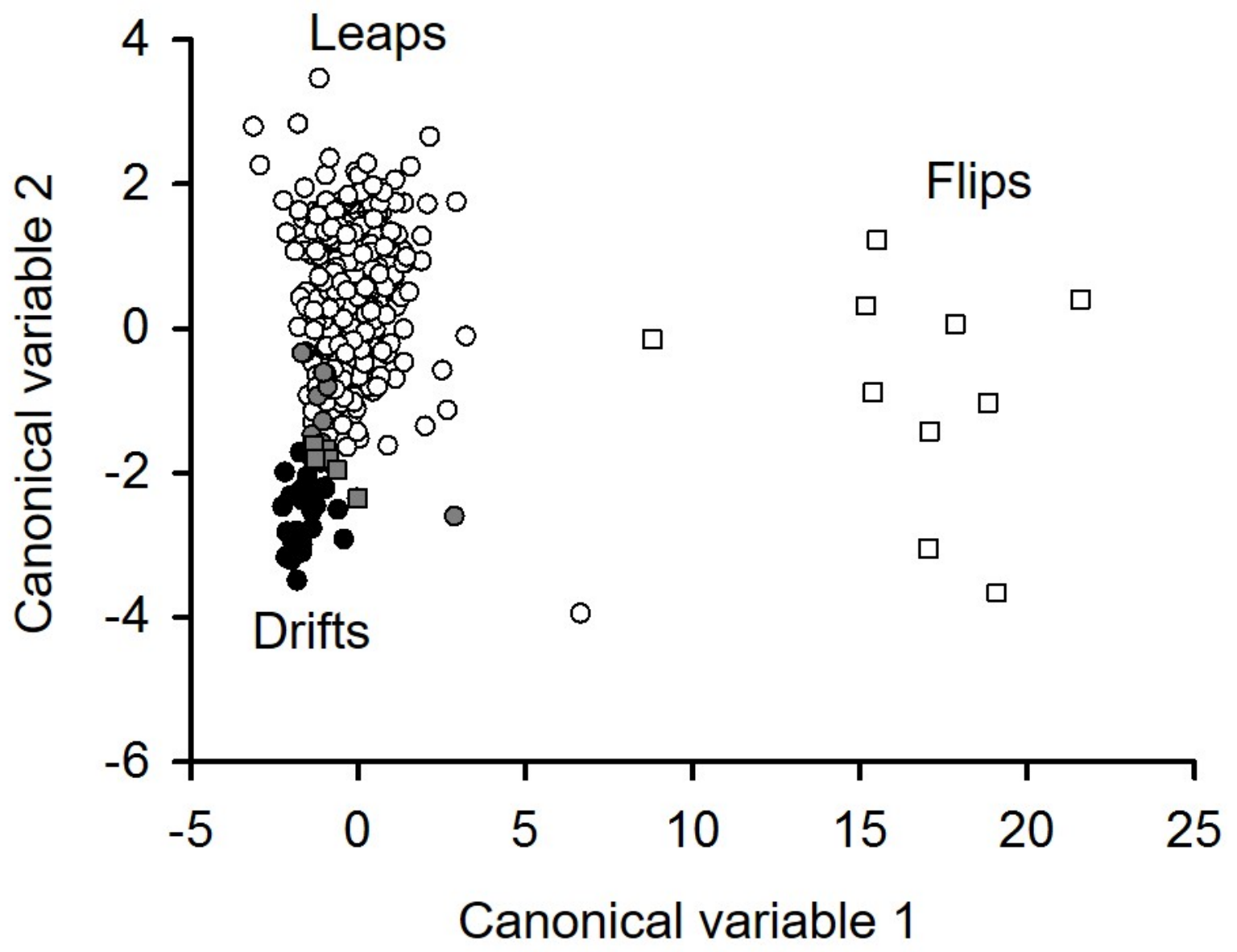


Figure 6:
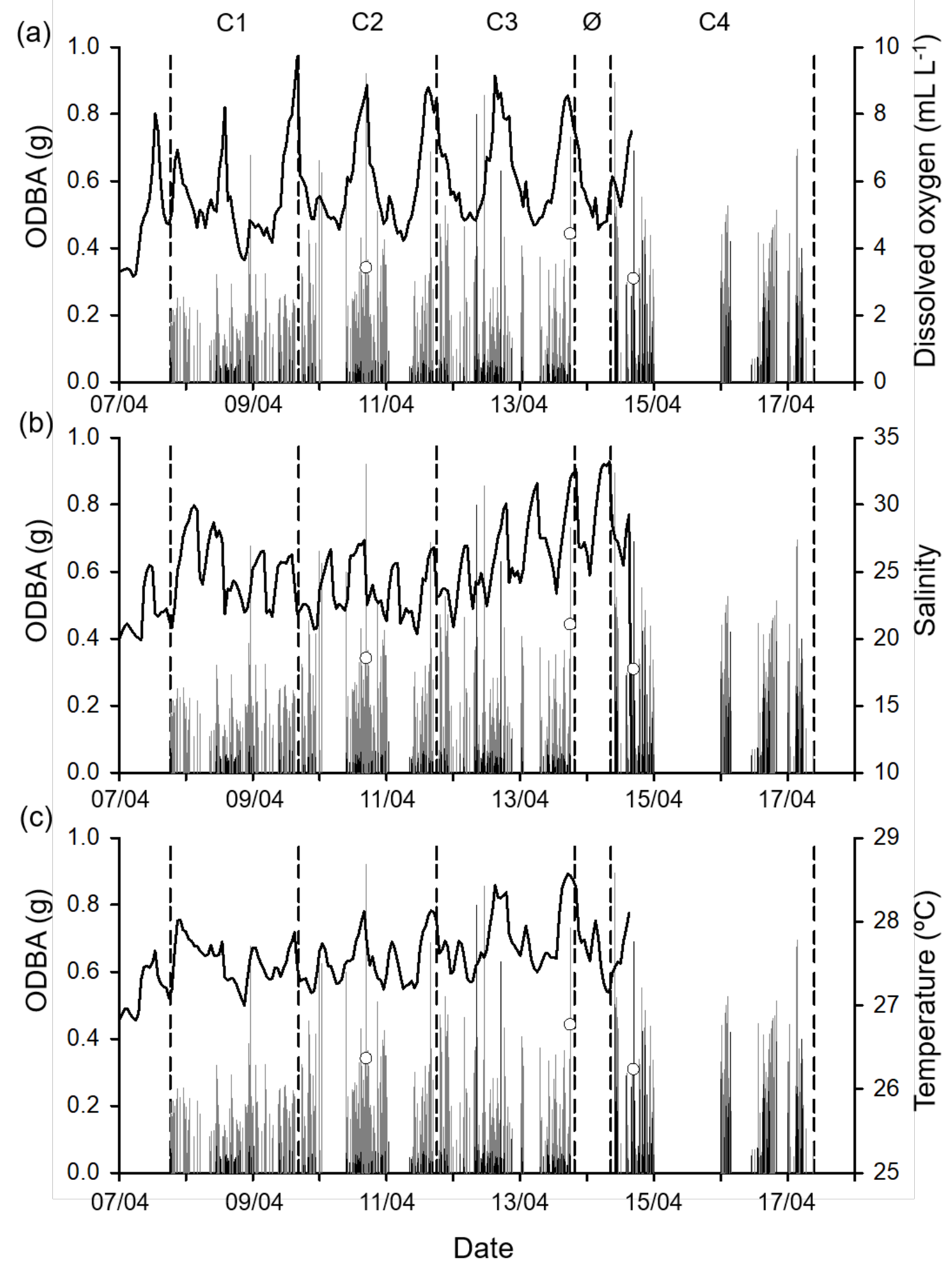

660 
661 Figure 7:
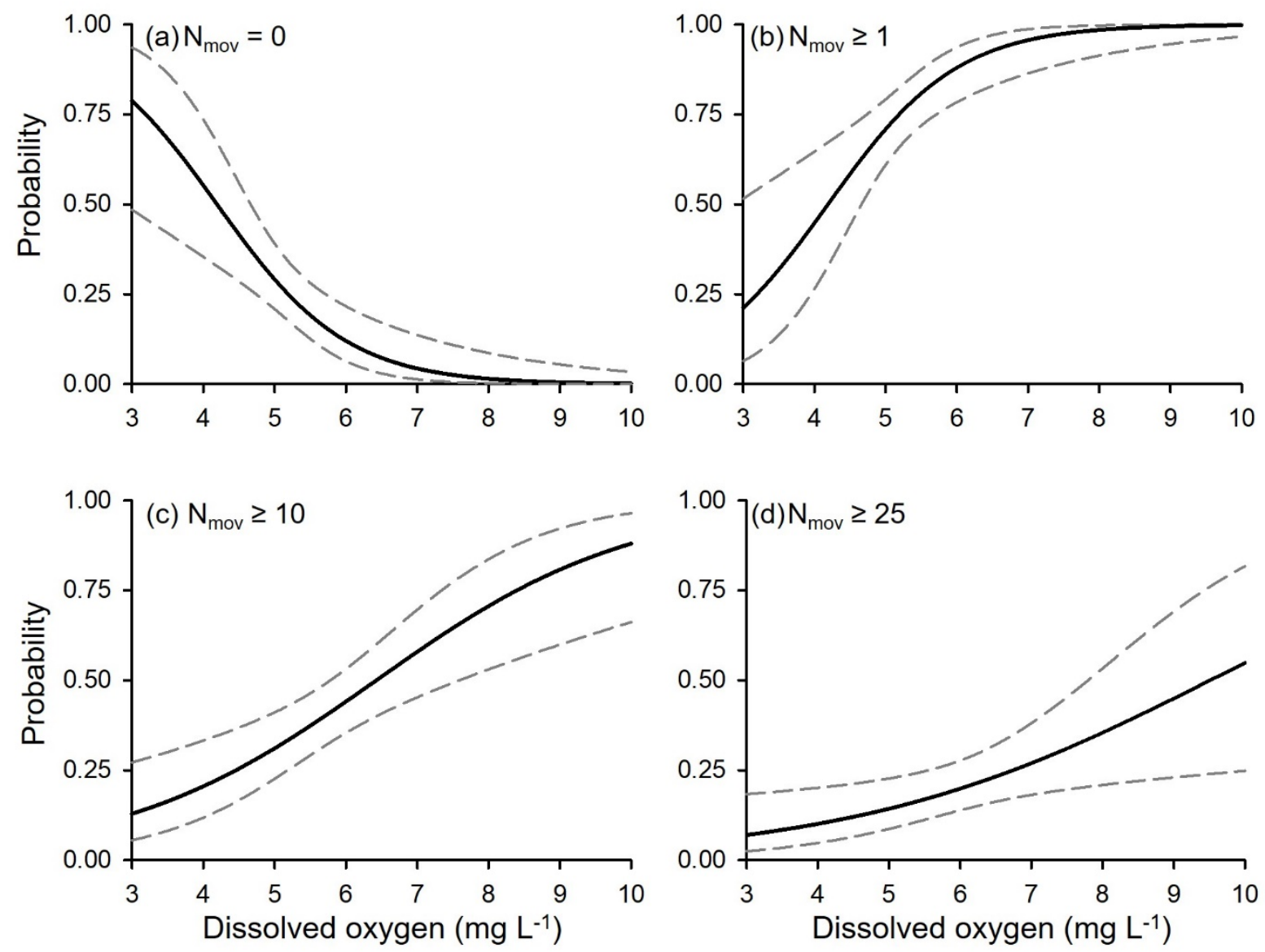
663 Table 1: Summary of the classified movements broken down by type for the nine queen

664 conch tagged with a 3D accelerometer. The first five queen conch in the table were used to

665 build the flexible discriminant model. The numbers between brackets correspond to the

666 number movements observed on the video and that were used to build the model. This model

667 was subsequently applied to the last four queen conch for which video recordings were not

668 available. For those individuals, the numbers in the leap, drift and flip column correspond to

669 the number of predicted movements.

Syphonal Tag length

$\begin{array}{ccccccccc}\begin{array}{c}\text { Conch } \\ \text { ID }\end{array} & \begin{array}{c}\text { length and } \\ \text { lip width } \\ (\mathrm{mm})\end{array} & \begin{array}{c}\text { cyphonal } \\ \text { length })\end{array} & \begin{array}{c}\text { Video } \\ \text { Recorded }\end{array} & \begin{array}{c}\text { No of } \\ \text { Leaps }\end{array} & \begin{array}{c}\text { No of } \\ \text { Drifts }\end{array} & \begin{array}{c}\text { No of } \\ \text { Flips }\end{array} & \text { Total } & \begin{array}{c}\text { Record } \\ \text { duration } \\ \text { (hh:mm) }\end{array} \\ \text { S1 } & 176-4 & 68 \% & \text { Yes } & 102(63) & 14(12) & 0 & 116(65) & 7: 25 \\ \text { S2 } & 212-11 & 57 \% & \text { Yes } & 154(101) & 2(2) & 0 & 156(103) & 1: 10 \\ \text { S3 } & 210-5 & 57 \% & \text { Yes } & 205(47) & 33(10) & 0 & 238(57) & 9: 15 \\ \text { J1 } & 180-0 & 67 \% & \text { Yes } & 198(59) & 34(13) & 0 & 232(62) & 9: 15 \\ \text { J2 } & 198-0 & 61 \% & \text { Yes } & 410(133) & 16(13) & 10(10) & 436(146) & 3: 30 \\ \text { C1 } & - & - & \text { No } & 578 & 39 & 0 & 617 & 45: 10 \\ \text { C2 } & - & - & \text { No } & 739 & 69 & 1 & 809 & 48: 30 \\ \text { C3 } & - & - & \text { No } & 821 & 109 & 1 & 931 & 47: 20 \\ \text { C4 } & - & - & \text { No } & 1116 & 94 & 1 & 1211 & 48: 35\end{array}$


671 Table 2: List of descriptors calculated using the acceleration time series of the three types of

672 movements (leap, dript and flips) classified from the queen conch video records. The

673 descriptors were used to build a flexible discriminant analysis to discriminate between the

674 movements of queen conch for which no video recordings were available.

675

\begin{tabular}{|c|c|}
\hline Notation & Descriptor \\
\hline $\mathrm{E}_{\mathrm{x}}$ & Surge signal energy $\left(g^{2}\right)$ \\
\hline $\mathrm{E}_{\mathrm{y}}$ & Sway signal energy $\left(\mathrm{g}^{2}\right)$ \\
\hline $\mathrm{E}_{\mathrm{z}}$ & Heave signal energy $\left(\mathrm{g}^{2}\right)$ \\
\hline $\mathrm{E}_{O D B A}$ & ODBA signal energy $\left(\mathrm{g}^{2}\right)$ \\
\hline $\operatorname{Max}_{\mathrm{x}}$ & Surge acceleration maximum (g) \\
\hline $\operatorname{Max}_{\mathrm{y}}$ & Sway acceleration maximum (g) \\
\hline $\operatorname{Max}_{\mathrm{z}}$ & Heave acceleration maximum (g) \\
\hline $\operatorname{Max}_{O D B A}$ & Maximum ODBA of the movement (g) \\
\hline $\operatorname{Mean}_{\mathrm{x}}$ & Mean surge acceleration (g) \\
\hline $\operatorname{Mean}_{\mathrm{y}}$ & Mean sway acceleration (g) \\
\hline $\operatorname{Mean}_{\mathrm{z}}$ & Mean heave acceleration $(\mathrm{g})$ \\
\hline Mean $_{O D B A}$ & Mean ODBA $(g)$ \\
\hline $\operatorname{Mean}_{x^{2}}$ & Mean squared surge acceleration $\left(\mathrm{g}^{2}\right)$ \\
\hline $\operatorname{Mean}_{\mathrm{y}^{2}}$ & Mean squared sway acceleration $\left(\mathrm{g}^{2}\right)$ \\
\hline $\operatorname{Mean}_{\mathrm{z}^{2}}$ & Mean squared heave acceleration $\left(\mathrm{g}^{2}\right)$ \\
\hline $\mathrm{T}$ & Movement duration (s) \\
\hline
\end{tabular}


677 Table 3: Logistic regression models exploring the relationship between the probability of

678 observing a given number of movements per hour $\left(\mathrm{N}_{\text {mov }}=0, \mathrm{~N}_{\text {mov }} \geq 1, \mathrm{~N}_{\text {mov }} \geq 10, \mathrm{~N}_{\text {mov }} \geq 25\right)$

679 and the environmental parameters (DO: dissolved oxygen concentration, S: salinity, T :

680 temperature, Tod : time of day). The odd ratio and AIC were only reported when the model

681 was statistically significant.

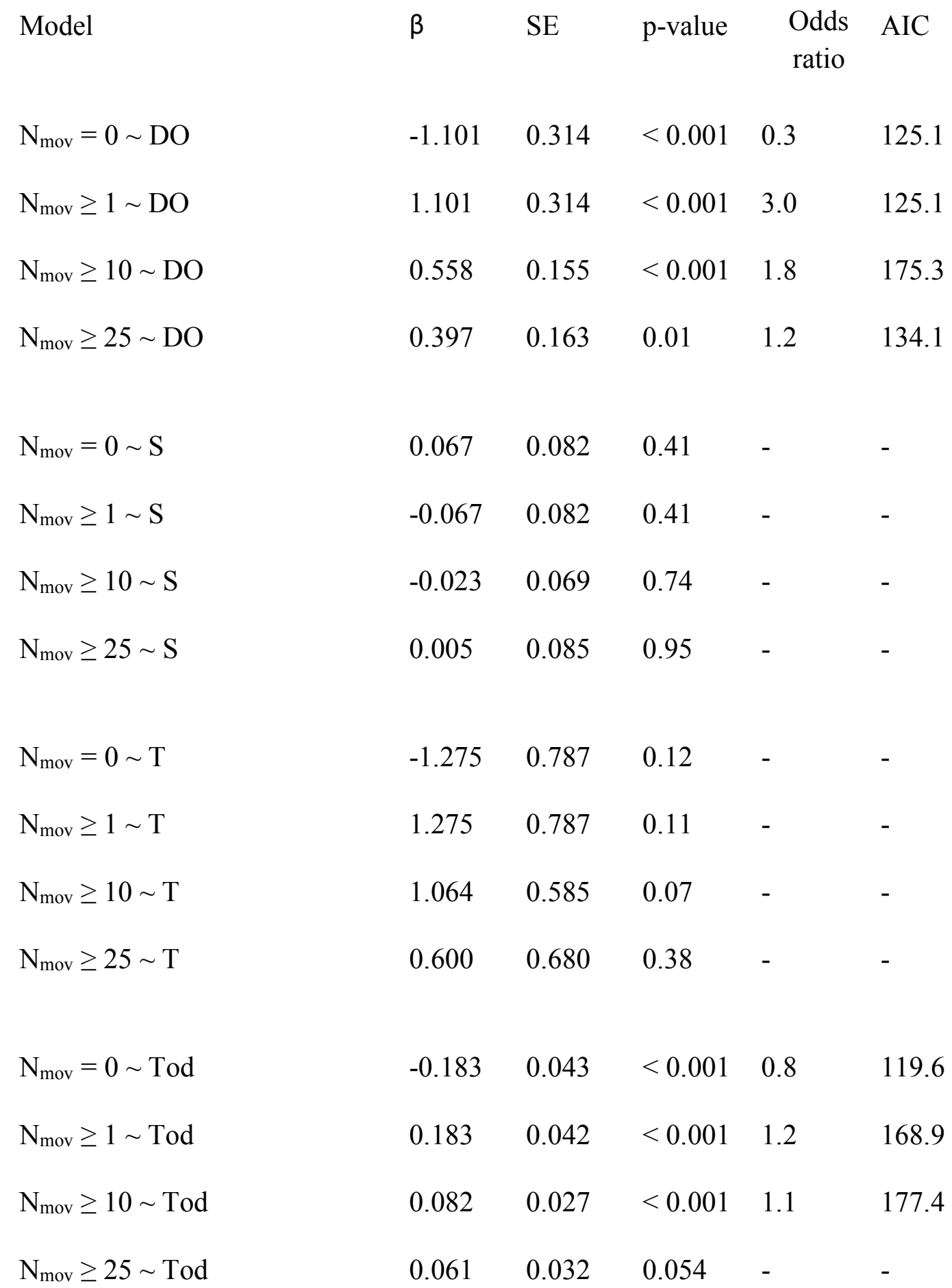




$\begin{array}{ccccccc}\mathrm{N}_{\text {mov }}=0 \sim \text { Tod + DO } & \text { Tod: } & -0.142 & 0.043 & <0.001 & 0.9 & 112.7 \\ & \text { DO: } & -1.011 & 0.395 & 0.01 & 0.4 & \\ & & & & & & \\ \mathrm{~N}_{\text {mov }} \geq 1 \sim \text { Tod + DO } & \text { Tod: } & 0.142 & 0.043 & <0.001 & 1.1 & 112.7 \\ & \text { DO: } & 1.01 & 0.269 & 0.01 & 2.7 & \\ & & & & & & \\ \mathrm{~N}_{\text {mov }} \geq 10 \sim \text { Tod + DO } & \text { Tod: } & 0.065 & 0.029 & 0.01 & 1.1 & 172.1 \\ & \text { DO: } & 0.421 & 0.162 & 0.01 & 1.5 & \\ & & & & & & - \\ \mathrm{N}_{\text {mov }} \geq 25 \sim \text { Tod + DO } & \text { Tod: } & 0.041 & 0.035 & 0.25 & - & -\end{array}$


685 Figure 1: Location of the ground-water-fed Xel-Ha inlet (represented by a black square) on 686 the Yucatan Peninsula (Mexico).

687

688 Figure 2: Photography of a queen conch carrying a 3D accelerometer (back cylinder in A) 689 recording the shell movements (in B) in Xel-Ha inlet in 2012. The proboscis (showed by the red arrow in C) extrudes from the shell during grazing and its movement is not recorded by

691 the accelerometer.

692

693 Figure 3: The three main movements of queen conch and their typical accelerograms: (a)

694 leap - the most frequent movements mainly used for grazing and long-distance travels, (b)

695 drift - used to rotate the shell to access close areas of sediment and (c) flip - made when the

696 conch shell is overturned. Note the scale differences on the y-axis for the three movement

697 types.

698

699 Figure 4: Visual representation of the three-main type of queen conch movement: (a) the 700 leap, (b) the drift, (c) the flip. The section, L1 to L4, D1 to D2 and F1 to F4 correspond to the 701 same naming on Figure 3.

703 Figure 5: Visual representation of the flexible discriminant model built using the acceleration

704 time series and video record of the five 2012 individuals. Five descriptors were retained to build the model: MeanODBA, MeanZ ${ }^{2}, \mathrm{~T}, \mathrm{Mean} \mathrm{Y}^{2}$ and MeanX $\mathrm{X}^{2}$. The leaps (white circles, $\mathrm{n}=$ 403), drifts (black circles, $\mathrm{n}=50$ ) and flips (white squares, $\mathrm{n}=10$ ) are relatively well 
707 discriminated with an error rate of less than $6 \%$ (leaps predicted as drift, $\mathrm{n}=16$ as grey

708 circles and drifts predicted as leaps, $\mathrm{n}=9$ as grey squares).

709

710 Figure 6: (a-c) Overall Dynamic Body Acceleration (ODBA, in g) records of four queen

711 conch recorded over a period of eight consecutive days in April 2011. Each vertical bar

712 indicates a conch movement and its associated ODBA (leap as grey bar, drift has black bar).

713 White circles represent flip movements. Movements were classified using the flexible

714 discriminant model. Dashed vertical lines indicate the start and end of each individual conch

715 record. No data was recorded during the period marked with a ø. In (a) oxygen, (b) salinity

716 and (c) temperature variations are represented as solid black lines. Oxygen concentration

717 follows a diel pattern (mg L-1), while the salinity and temperature $\left({ }^{\circ} \mathrm{C}\right)$ follow a tidal pattern.

718

719 Figure 7: Probability curves of the logistic regression models linking the probability of

720 observing: (a) no movement $(\mathrm{Nmov}=0$, black line), (b) at least one movement (Nmov $\geq 1$,

721 upper black line) (c) at least ten movements (Nmov $\geq 10$, middle black line) and (d) at least

72225 movement (Nmov $\geq 25$, middle black line) per hour in function of the dissolved oxygen concentration. Grey dashed lines represent the 95\% confidence interval for each model. 


\section{Supplementary Methods 1}

725 A 3D accelerometer typically records acceleration in its own orthonormal coordinate system.

726 If fixed arbitrarily on the animal the accelerometer axes will not be aligned with the

727 orthonormal Earth system, which is ideally used to interpret the movement in a commonly

728 used framework, distinguishing surge (x axis, forward/backward), sway (y axis, sideways)

729 and heave ( $\mathrm{z}$ axis, up/down). We thus need to transform the raw acceleration into the Earth

730 system using a $3 \mathrm{D}$ rotation matrix. To build this matrix, the rotation angles, $\theta_{\mathrm{x}}, \theta_{\mathrm{y}}$ and $\theta_{\mathrm{z}}$

731 around the three axes of the accelerometers were determined by performing a calibration

732 procedure. At the end of each in-situ recording session, the animal was removed from the

733 water, carried carefully to the laboratory and laid on a horizontal surface. A succession of

734 forward, downward and up/down movements (corresponding to movements following the

735 axis of the earth orthonormal system) was then manually performed. In order to minimise the

736 effect of handling of the animal on its movement behaviour, this calibration which required

737 removal of the animal from the water was performed post-observation. We then extracted the

738 points with the maximum acceleration corresponding to these calibration movements and

739 applied an axis-angle methodology to determine the angles of the rotation matrix and convert

740 the data to the Earth system. The data obtained contains a static acceleration component, due

741 to gravity, equal to $1 \mathrm{~g}$ and a dynamic acceleration component, equal to zero, when the

742 animal is immobile and equal to the acceleration measured at the animal's centre of mass

743 during a movement. 
744 Electronic supplements

745 Electronic supplement 1. Example of a queen conch performing a leap.

746

747 Electronic supplement 2. Example of a queen conch performing a drift.

748

749 Electronic supplement 3. Example of a manually overturned queen conch performing a flip

750 to restore standard position. 